\title{
Left ventricle accessory antero-septal papillary muscle: an echocardiography and cardiac MRI case-series in controls and hypertrophic obstructive cardiomyopathy patients
}

\author{
George Angheloiu ${ }^{1}$ and Robert Biederman ${ }^{2}$ \\ ${ }^{1}$ University of Pittsburgh Medical Center \\ ${ }^{2}$ Allegheny General Hospital - Western Pennsylvania Hospital Medical Education \\ Consortium
}

August 11, 2020

\begin{abstract}
Background. We studied by means of echocardiography and cardiac MRI (CMR) the occurrence of an accessory papillary muscle that unites mostly the left ventricle (LV) apex with the basal or mid antero-septum. Methods. We included all good quality echocardiography and CMR studies as reviewed by two cardiologists and assessed the occurrence of a contractile papillary muscle situated between the LV apex and antero-septum. Results. A contractile accessory papillary muscle situated between the LV apex and the antero-septum was seen in $100 \%$ of HOCM patients and $62 \%$ of control patients ( $\mathrm{p}=0.05)$ in the CMR images acquired from a total of $22 \mathrm{HOCM}(9)$ and control (13) patients. The same structure was observed in 241 patients representing $69.5 \%$ of all-comers echocardiography studies. The age was $69 \pm 17$ years on average in the echocardiography arm, patients harboring the antero-septal accessory muscle being older $(71.6+15.7$ years old vs $63.5 \pm 18.1$ for those without, $\mathrm{p}=0.0005$ ). We exemplify this structure by parasternal long axis still echocardiography images and clips from 24 patients and CMR SSFP still images and a clip from two HOCM patients and one control. Conclusion. A contractile accessory papillary muscle was observed in more than half of the all-comer echocardiography studies, and in all HOCM patients in the CMR arm. Further research is needed to fully characterize the anatomical and physiological significance of this structure attaching in the immediate vicinity of the LVOT in HOCM and control patients.
\end{abstract}

\begin{abstract}
Background. We studied by means of echocardiography and cardiac MRI (CMR) the occurrence of an accessory papillary muscle that unites mostly the left ventricle (LV) apex with the basal or mid anteroseptum.

Methods. We included all good quality echocardiography and CMR studies as reviewed by two cardiologists and assessed the occurrence of a contractile papillary muscle situated between the LV apex and anteroseptum.

Results. A contractile accessory papillary muscle situated between the LV apex and the antero-septum was seen in $100 \%$ of HOCM patients and $62 \%$ of control patients $(\mathrm{p}=0.05)$ in the CMR images acquired from a total of $9 \mathrm{HOCM}$ and 13 control patients. The same structure was observed in 241 patients representing $69.5 \%$ of all-comers echocardiography studies. The age was $69 \pm 17$ years on average in the echocardiography arm, patients harboring the antero-septal accessory muscle being older $(71.6+15.7$ years old vs $63.5 \pm 18.1$ for those without, $\mathrm{p}=0.0005)$. We exemplify this structure by parasternal long axis still echocardiography images and clips from 24 patients and CMR SSFP still images and a clip from two HOCM patients and one control.
\end{abstract}


Conclusion . A contractile accessory papillary muscle was observed in more than half of the all-comer echocardiography studies, and in all HOCM patients in the CMR arm. Further research is needed to fully characterize the anatomical and physiological significance of this structure attaching in the immediate vicinity of the LVOT in HOCM and control patients.

Introduction. We studied the occurrence of an accessory papillary muscle that unites the left ventricle (LV) apex with the basal or mid antero-septum in an echocardiography arm as well as a cardiac MRI (CMR) arm of the study as reviewed by two cardiologists. Patients were included if they were 18 or older. Echocardiography images were analyzed in the parasternal long and short axis. All-comers from an interval time of 21 months were included in the echocardiography arm and poor image resolution studies were excluded. In the CMR arm, a HOCM as well as an age- and gender- controlled control group were selected. CMR patients and controls were scanned using a Siemens Espree machine. Images were acquired using SSFP 2,3 , and 4 chamber as well as short axis views.

A CMR diagnosis of HOCM was made if left ventricular hypertrophy accompanied by systolic anterior motion (SAM) of the mitral valve apparatus with obstruction of the left ventricle outflow tract flow were noted. An IRB exemption was granted.

\section{Case-Series Report .}

Echocardiography arm. 371 echocardiography studies were reviewed. 24 were excluded due to poor echocardiographic definition of the LV antero-septal region, leaving 347 patients to be analyzed. The accessory antero-septal papillary muscle was seen in 241 patients representing $69.5 \%$ of all good quality studies. The age was $69 \pm 17$ years on average, patients harboring the antero-septal accessory muscle being older (71.6 +15.7 years for patients with this structure vs $63.5 \pm 18.1$ for those without, $\mathrm{p}=0.0005) .47 \%$ of patients included were women. The occurrence of the antero-septal accessory muscle was similar in men and women (70\% vs $69 \%)$.

We further describe various features of the accessory papillary muscle particular to four separate patients (Clips 1-4, Figures 1-4) in the echocardiography and 2 HOCM patients and one control in the CMR arm (Clip 5, Figure 5), and also list for abundant proof figures and clips of an additional 20 patients (Clips 6-25, Figures 6-25) in the echocardiography arm.

Figure $1 \mathrm{a}$ and $1 \mathrm{~b}$ (diastolic frames) and Clips 1 and 2 show the structure in an 87-year-old patient admitted for severe anemia and fatigue. The thickness is approximately $8 \mathrm{~mm}$ in these views and it has the same echogenic appearance as the rest of the myocardium. At the LV base the myocardial structure can be seen in the short axis view straddling between the antero-lateral wall and the antero-septum forming a short roof beneath the anteroseptal basal wall (Figures 1 and 2) continuing thereafter with the roof of the LV outflow tract (LVOT).

The papillary accessory muscle ( $5 \mathrm{~mm}$ thick) is seen in diastole using an echo contrast method (Figures 2a and $2 \mathrm{~b}$ and as well as Clips 3 and 4 ) in a 63-year-old admitted for a non-occlusive pulmonary embolism.

Figures 3a and 3b and Clips 3 and 4 identify two parallel accessory pap antero-septal muscle strands (systolic frames, $5 \mathrm{~mm}$ thick) in a 54-year-old admitted for atrial fibrillation. One bundle inserts into the mid anteroseptum (yellow arrow) while the second into the basal septum (red arrow). They are both parallel with the antero-lateral and postero-medial papillary muscles (pink and yellow dots respectively) creating together, along with the mitral anterior leaflet, a tunnel leading into the LVOT.

In these first three patients one can notice the bulky basal antero-septum (15 mm at level of mitral valve leaflets in diastole, Figure 1a) with a very convex shape - "sigmoid septum", onto which the accessory papillary structure inserts itself.

In a fourth - 56-year-old patient, one can notice in Figures $4 \mathrm{a}$ and $4 \mathrm{~b}$ a thin muscular-fibrous structure (1 $\mathrm{mm}$ thick) inserting into the mid antero-septum. 
The thickness of the antero-septum at the level of the mitral valve leaflets was 15, 14, 10 and $8 \mathrm{~mm}$ respectively in these four patients.

CMR arm. $100 \%$ of 9 HOCM patients and $62 \%$ ( 8 of $13, \mathrm{P}=0.05$ ) of controls demonstrated an accesory papillary muscle connecting the left ventricle basal antero-septum with the apex, noticeable on the long axis view. This particular structure contracts during systole as seen in Figure 5 (red arrow) in panels "b" and "e" (mid-systole) and "c" and "f" (end-systole) in two HOCM patients (panels a-c and d-f respectively). A severe and a moderate SAM of the mitral apparatus are seen in panels a-c and d-f respectively in these two HOCM patients.

Clip 5 demonstrates a third patient with HOCM and severe LV hypertrophy with SAM of the mitral valve along with moderate mitral regurgitation. One can distinctly notice a thin contractile myocardial strand uniting the basal antero-septum with the LV apex.

The papillary muscle was not present in panels g-i of one control subject. There was no LVOT obstruction at end systole in this patient and no accessory anteroseptal papillary muscle - as depicted in panel "i".

An additional 20 patients' parasternal echocardiography long axis clips (clips 6-25) are presented along with their corresponding still frames (Figures 6-25), all demonstrating an accessory papillary muscle with features similar with those illustrated above. In one patient the accessory papillary muscle stretches from the basal antero-septum to the mid infero-lateral wall instead of the apex (Figure 7).

Discussion. We present in this report 241 patients where a contractile papillary myocardial structure (thickness from 8 to $1 \mathrm{~mm}$ ) is seen stretching between the LV apex and the basal or mid antero-septum. The structure runs parallel with the antero-lateral and postero-medial papillary muscles and the three papillary muscular bundles along with the mitral anterior leaflet form a tunnel leading into the LVOT. One can imagine a possible LVOT obstructive phenomenon between the four structures in systole. Clip 5 is a steady SSFP CMR clip demonstrating this phenomenon in a 65 year-old. The antero-septal accessory papillary muscle was more common in older patients. This could be related to the fact that LV hypertrophy is more common with advanced age. ${ }^{1}$ Two of the four echocardiography cases illustrated had moderate LV hypertrophy, and three presented a prominent "sigmoid septum" at the level of the accessory muscle insertion. While false LV cords with no apparent contraction, and an anteriorly displaced papillary muscle inserting onto the base of the anterior mitral leaflet have been previously described, ${ }^{2}$ no series reports have looked at a contractile papillary muscle inserting into the antero-septal area.

Limitations. We analyzed in this report all contractile myocardial bundles inserting into the antero-septum, including those with a low thickness such as $1 \mathrm{~mm}$. Also, a certain selection bias in a first study describing a new structure cannot be excluded. Larger additional studies are needed to exactly determine the occurrence and definition of the antero-septal accessory papillary muscle.

Conclusion. We describe in this report an accessory papillary muscle uniting mostly the LV apex with the basal anteroseptum in the LVOT vicinity.

References:

1. Cuspidi C, Meani S, Sala C, Valerio C, Negri F, Mancia G. Age related prevalence of severe left ventricular hypertrophy in essential hypertension: echocardiographic findings from the ETODH study.Blood Press . 2012;21:139-145.

2. Yang HS, Lee KS, Chaliki HP, Tazelaar HD, Lusk JL, Chandrasekaran K, Tajik AJ. Anomalous insertion of the papillary muscle causing left ventricular outflow obstruction: visualization by real-time three-dimensional echocardiography. Eur J Echocardiogr . 2008;9:855-60.

Markers:

Red or yellow arrows - anteroseptal accessory papillary muscle. White arrow - anteroseptum. Pink and yellow dots - regular papillary muscles. White dot - anterior mitral valve leaflet. 
Abbreviations:

A Fib- atrial fibrillation

AVR- aortic valve replacement

CAD- coronary artery disease

CMR - cardiac MRI

COPD- chronic obstructive pulmonary disease

CP- chest pain

HTN- hypertension

LVOT - left ventricle outflow tract

PLAX - parasternal long axis view

SAX - short axis view

Captions:

Figure 1 and Clips 1 and $2.8 \mathrm{~mm}$ thick accessory papillary muscle inserting into the basal anteroseptum at the level where the latter adapts to a sigmoid shape (1a, PLAX). The papillary muscle creates a roof under the anteroseptum (1b, SAX), roof that continues then with the LVOT superior wall.

Figure 2 and Clips 3 and 4. Longitudinal (2a) and short axis (2b) contrast echo images in a 63 year old illustrating the accessory papillary muscle in diastole with a contrast enhanced empty space seen between the anteroseptum and the papillary muscle.

Figure 3. Systolic view of long (3a) and short axis (3b) representing two accessory papillary muscle inserting into the mid and basal anteroseptum. The muscle fascicles are parallel with the postero-medial (yellow) and antero-lateral (pink) papillary muscles creating along with the anterior mitral leaflet a tunnel leading into the LVOT.

Figure 4. $1 \mathrm{~mm}$ thick accessory muscle fiber inserting into the mid anteroseptum (PLAX and SAX).

Figure 5. CMR 3-chamber view images of a two HOCM patients and one control. Panels a-f HOCM patients and g-i controls; panels a, d and $\mathrm{g}$ - diastole; b,e and h - mid-systole; c, f and i - end-systole.

Clip 5. Steady state free precession CMR clip of a 65-year-old patient with hypertrophic obstructive cardiomyopathy. One can notice the SAM of mitral valve as well as the antero-septal hypertrophy with a thin contractile antero-septal accessory muscle uniting the apex with the basal antero-septum.

Figure 6 and Clip 6. 63-year-old with HTN and COPD admitted for small bowel obstruction and surgery (PLAX).

Figure 7 and Clip 7. 74-year-old with HTN and hydrocephalus admitted for shunt placement. In this particular patient the pap muscle inserts at the base anteroseptum and then in the mid infero-lateral wall (PLAX).

Figure 8 and Clip 8. Echo-contrast image in a 77-year-old with HTN, CAD, CABG, CHF admitted for complete AV block (PLAX).

Figure 9 and Clip 9. 89-year-old seen in the office for dizziness and a cardiac murmur (PLAX).

Figure 10 and Clip 10. 48-year-old with HTN, status post aortic dissection, aortic root repair and AVR (PLAX).

Figure 11 and Clip 11. 74-yer-old with HTN, CAD, diabetes, admitted for CP (PLAX). 
Figure 12 and Clip 12. 72-year-old with hyperlipidemia and no significant cardiac history (PLAX).

Figure 13 and Clip 13. Echo contrast image in a 58-year-old with HTN admitted for CP (PLAX).

Figure 14 and Clip 14. 76-year-old with HTN, diabetes and CAD seen in office for sleep apnea (PLAX).

Figure 15 and Clip 15. 72-year-old with HTN, diabetes, obesity admitted for dyspnea on exertion (PLAX).

Figure 16 and Clip 16. 71-year-old with HTN admitted for dyspnea and hypertensive urgency (PLAX).

Figure 17 and Clip 17. 72-year-old with paroxysmal A Fib, tri-fascicular atrioventricular block admitted for syncope (PLAX).

Figure 18 and Clip 18. Echo-contrast image in a 70-year old with HTN, hyperlipidemia and CAD admitted for CP (PLAX).

Figure 19 and Clip 19. 43-year-old with HTN, diabetes admitted for numbness of left side of his body (PLAX).

Figure 20 and Clip 20. 80-year-old with HTN, hyperlipidemia admitted for dyspnea (PLAX).

Figure 21 and Clip 21. 61-year-old with HTN, admitted for bleeding (PLAX).

Figure 22 and Clip 22. 91-year-old with HTN admitted for small bowel obstruction (PLAX).

Figure 23 and Clip 23. 76-year-old admitted for hernia repair (PLAX).

Figure 24 and Clip 24. 82-year-old seen in the office for aortic valve stenosis (PLAX).

Figure 25 and Clip 25. 78-year-old with HTN, status post aortic root replacement and AVR (PLAX).

Figure $1.8 \mathrm{~mm}$ thick accessory pap muscle inserting into the basal anteroseptum at the level where the latter adapts to a sigmoid shape (1a, PLAX). The muscle creates a roof under the anteroseptum (1b, SAX), roof that continues then with the LVOT superior wall.

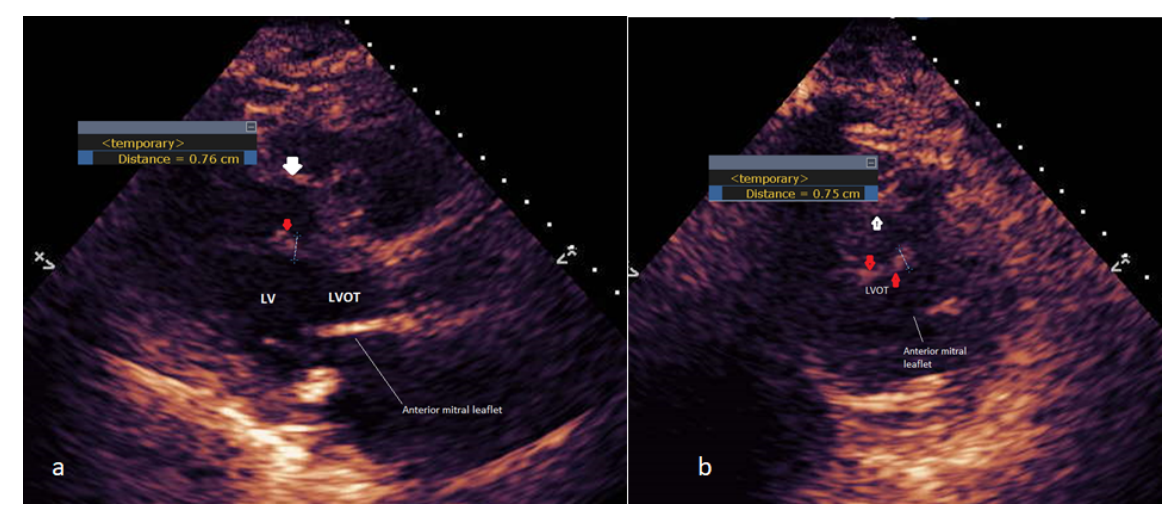




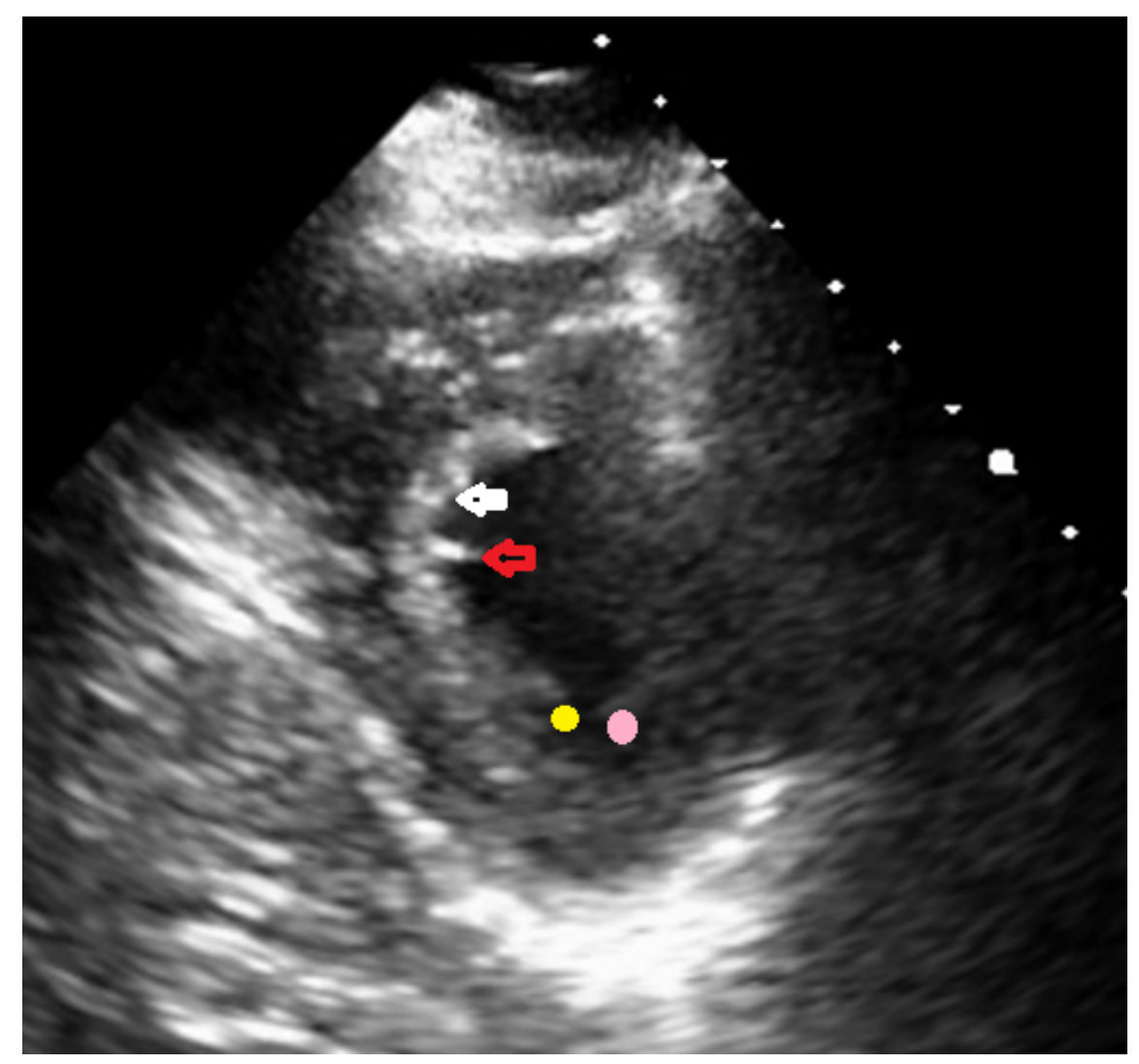

Figure 2. Longitudinal (2a) and short axis (2b) contrast echo images illustrating the accessory papillary muscle in diastole with a contrast enhanced empty space seen between the anteroseptum and the papillary muscle.

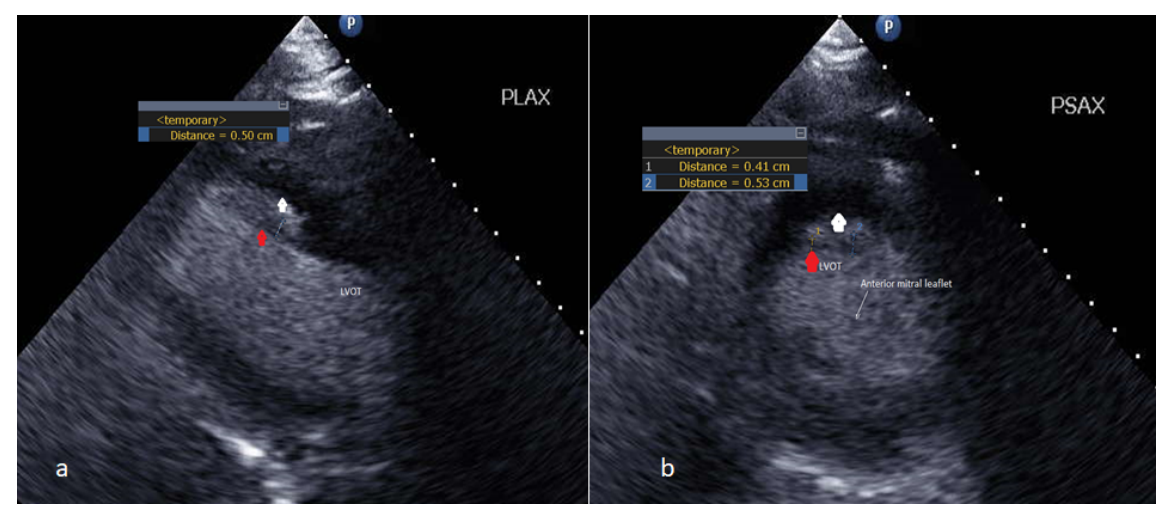

Figure 3. Systolic view of long (3a) and short axis (3b) representing two accessory papillary muscle inserting into the mid and basal anteroseptum. The muscle fascicles are parallel with the postero-medial (yellow) and antero-lateral (pink) papillary muscles creating along with the anterior mitral leaflet a tunnel leading into the LVOT. 

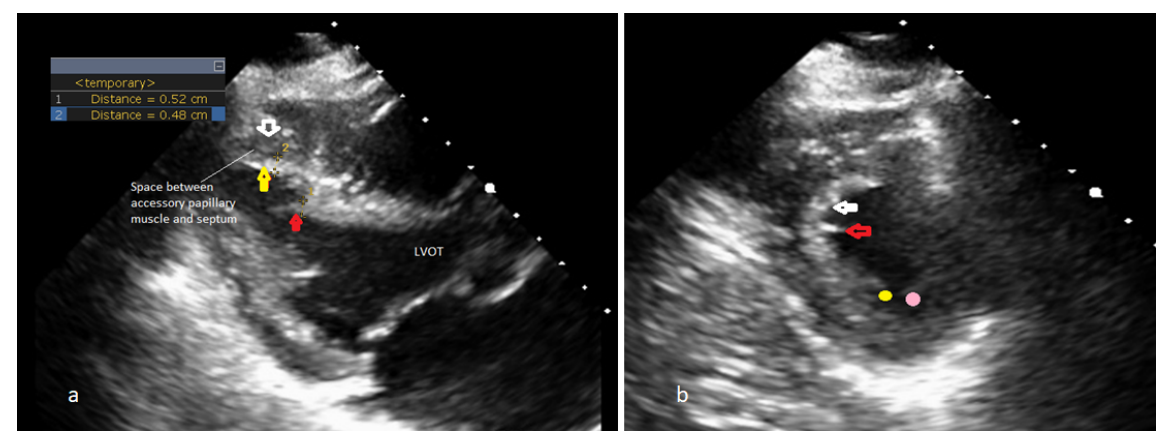

Figure 4. $1 \mathrm{~mm}$ thick accessory muscle fiber inserting into the mid anteroseptum (PLAX and SAX).
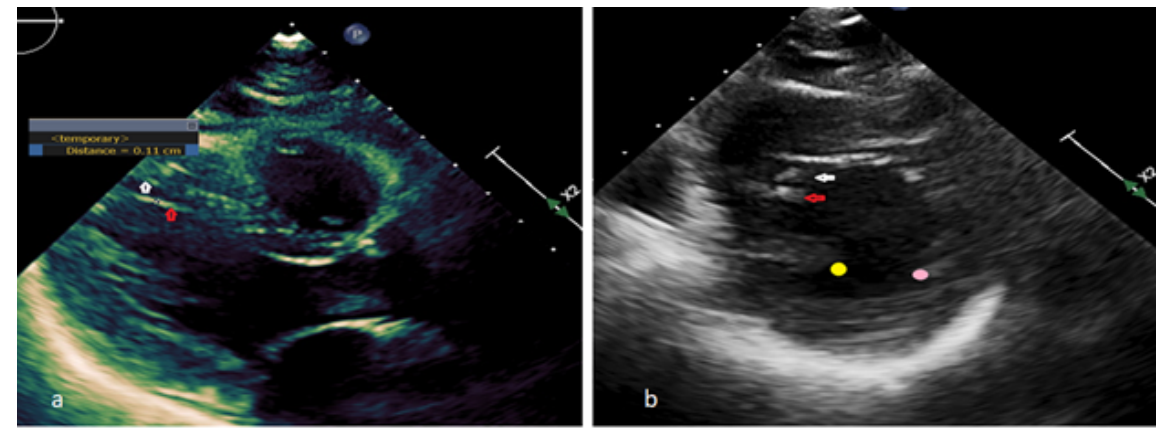

Figure 5. CMR 3-chamber view images of a two HOCM patients and one control. Panels a-f HOCM patients and g-i controls; panels a, d and g - diastole; b,e and h- mid-systole; c, f and i - end-systole.

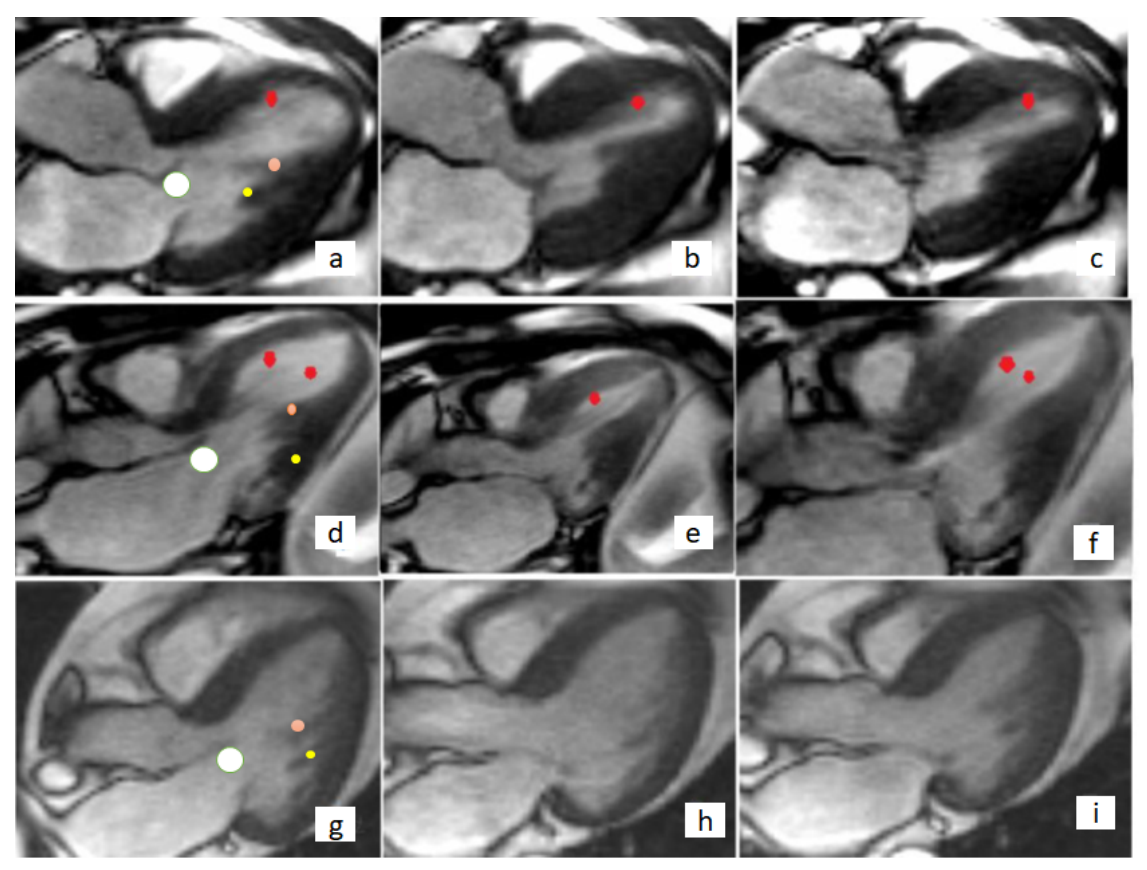


Figure 6. 63-year-old with HTN and COPD admitted for small bowel obstruction surgery (PLAX).

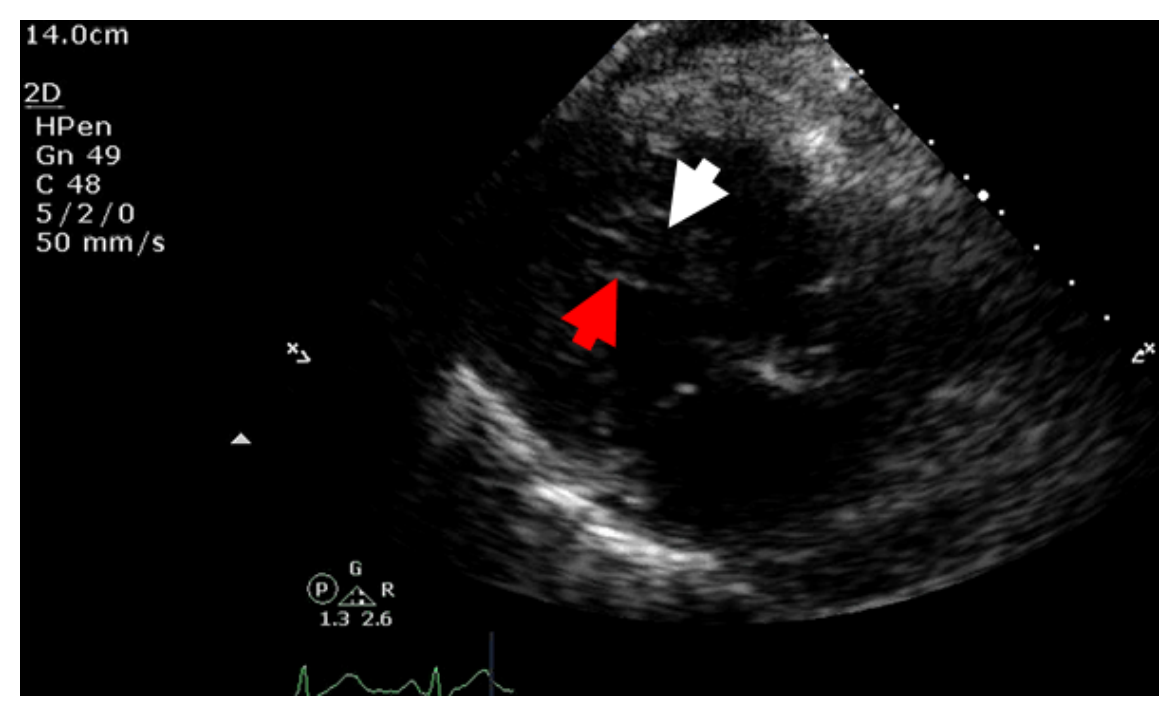

Figure 7. 74-year-old with HTN and hydrocephalus admitted for shunt placement. In this particular patient the papillary muscle inserts at the base anteroseptum and then on the mid infero-lateral wall (PLAX).

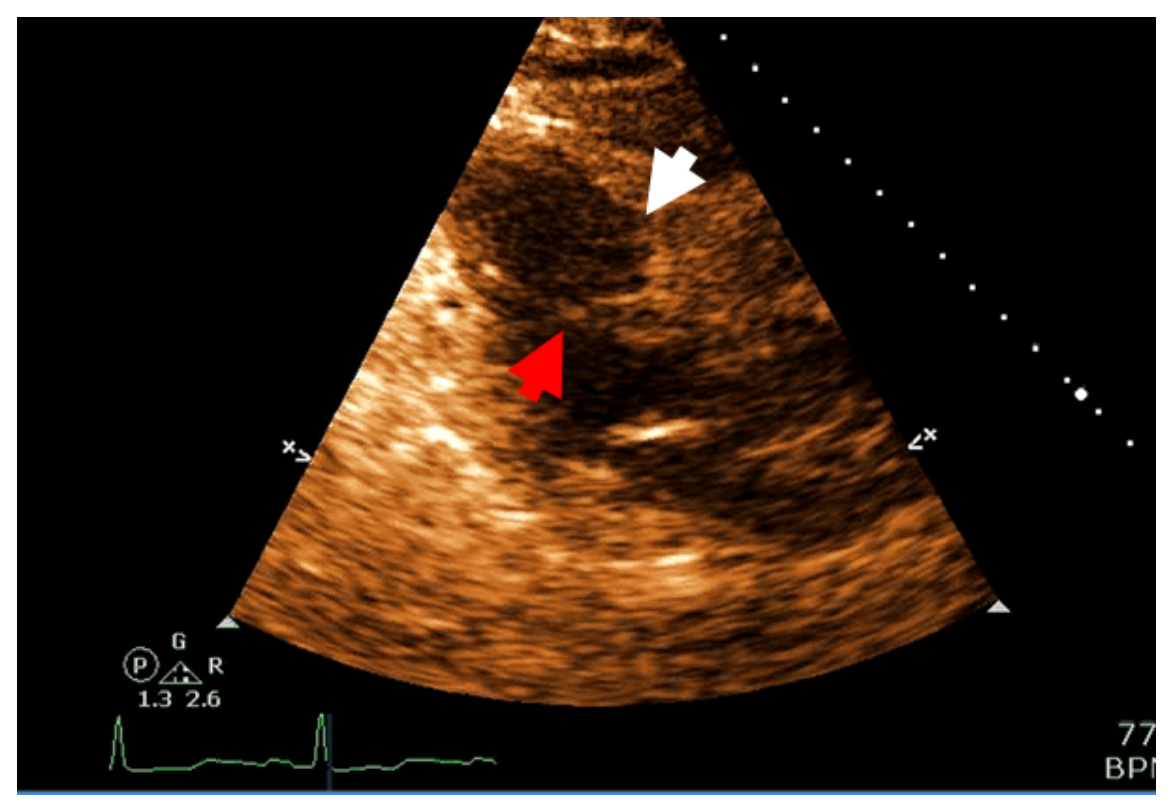

Figure 8. Echo-contrast image in a 77-year-old with HTN, CAD, CABG, CHF admitted for complete AV block (PLAX). 


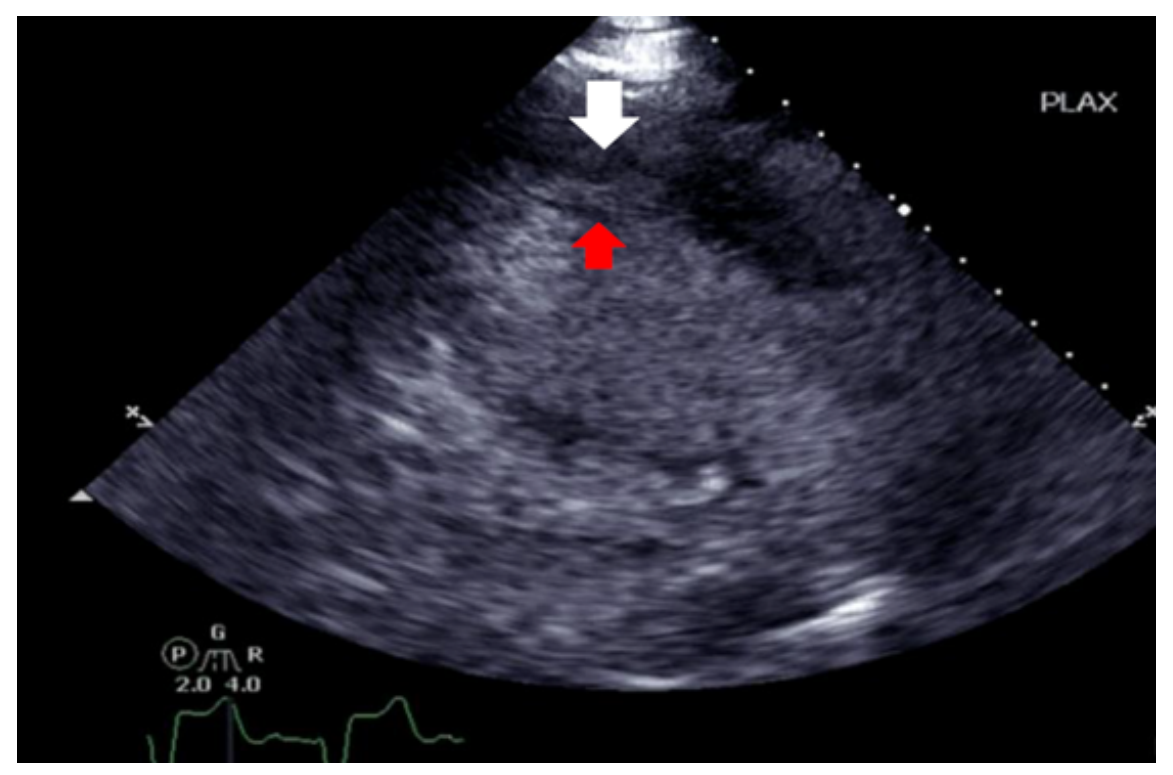

Figure 9. 89-year-old seen in the office for dizziness and a cardiac murmur (PLAX).

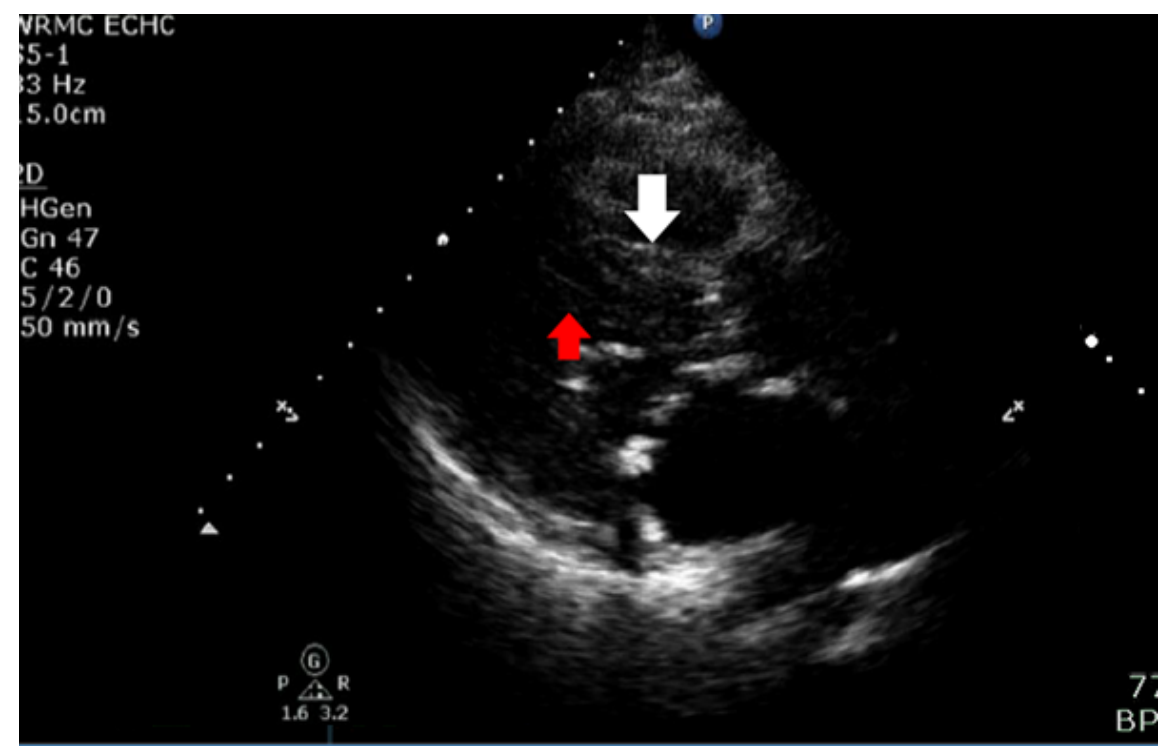

Figure 10. 48-year-old with HTN, status post aortic dissection, aortic root repair and AVR (PLAX). 

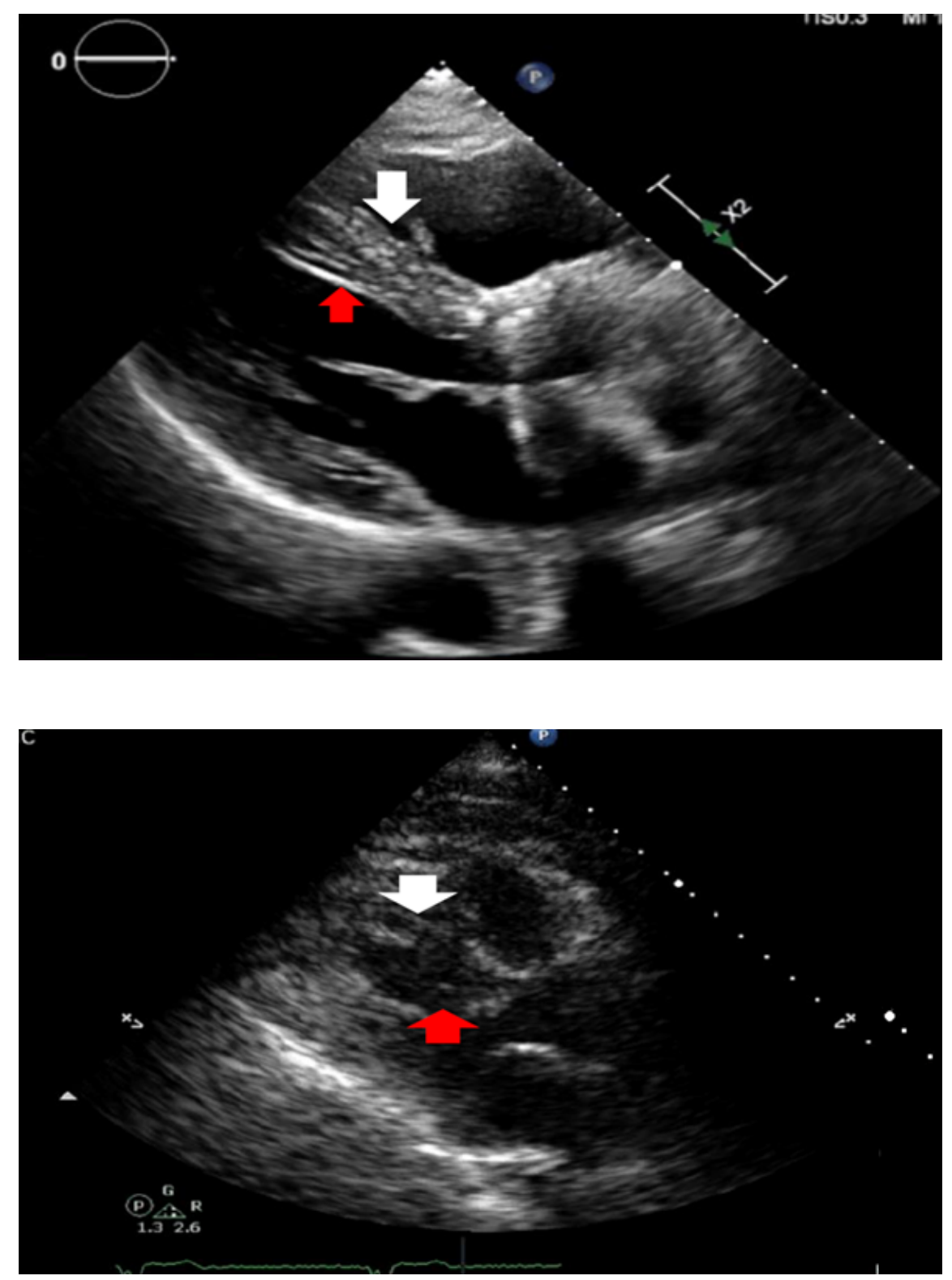

Figure 11. 74-yer-old with HTN, CAD, diabetes, admitted for CP (PLAX).

Figure 12. 72-year-old with hyperlipidemia and no significant cardiac history (PLAX). 


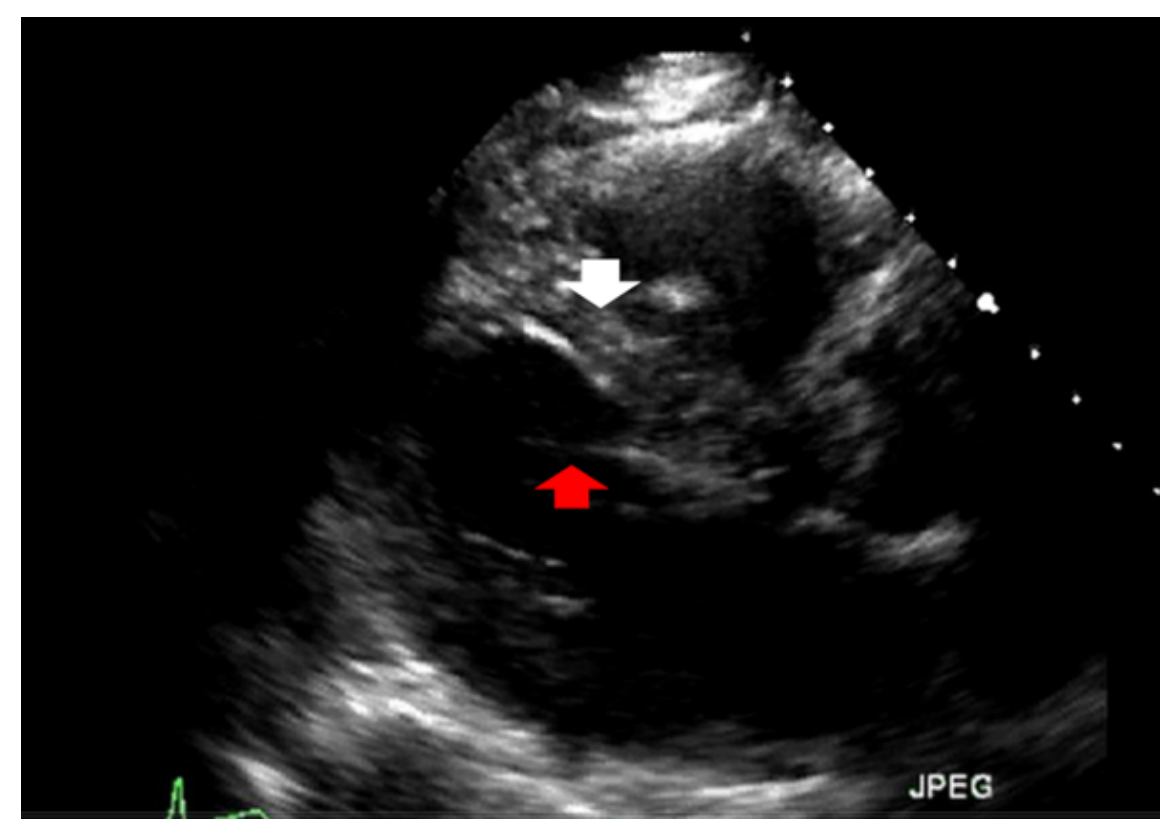

Figure 13. Echo contrast image in a 58-year-old with HTN admitted for CP (PLAX).

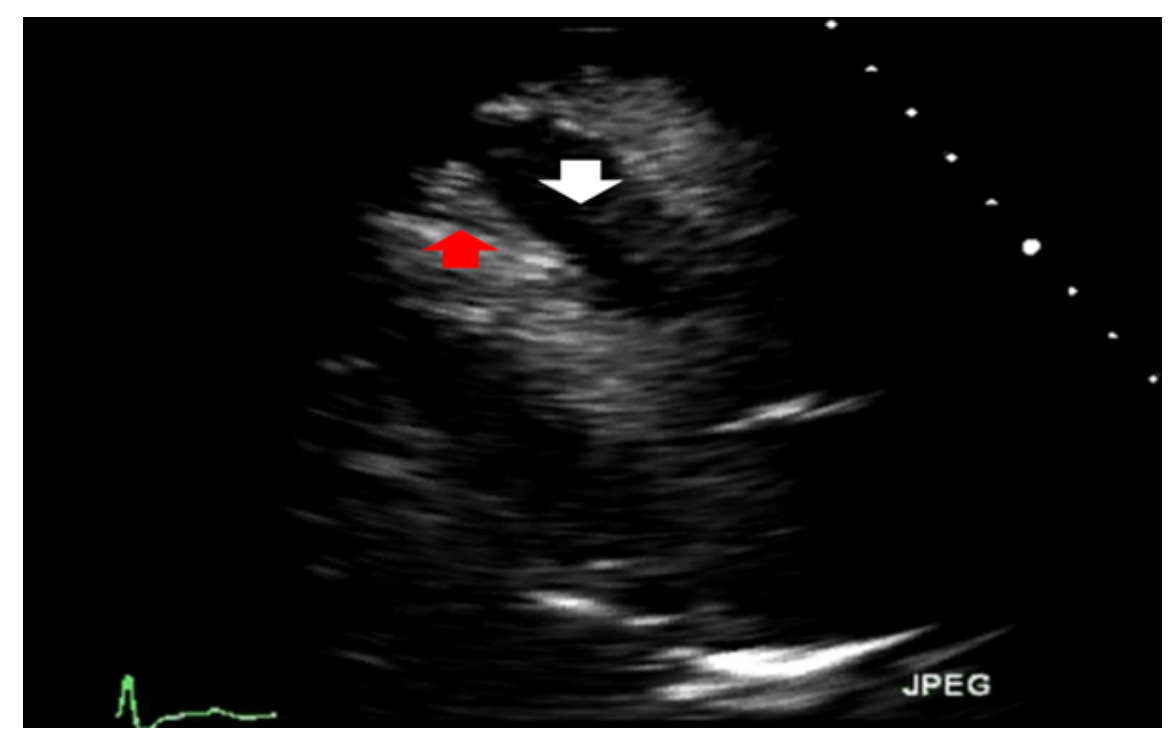

Figure 14. 76-year-old with HTN, diabetes and CAD seen in office for sleep apnea (PLAX). 


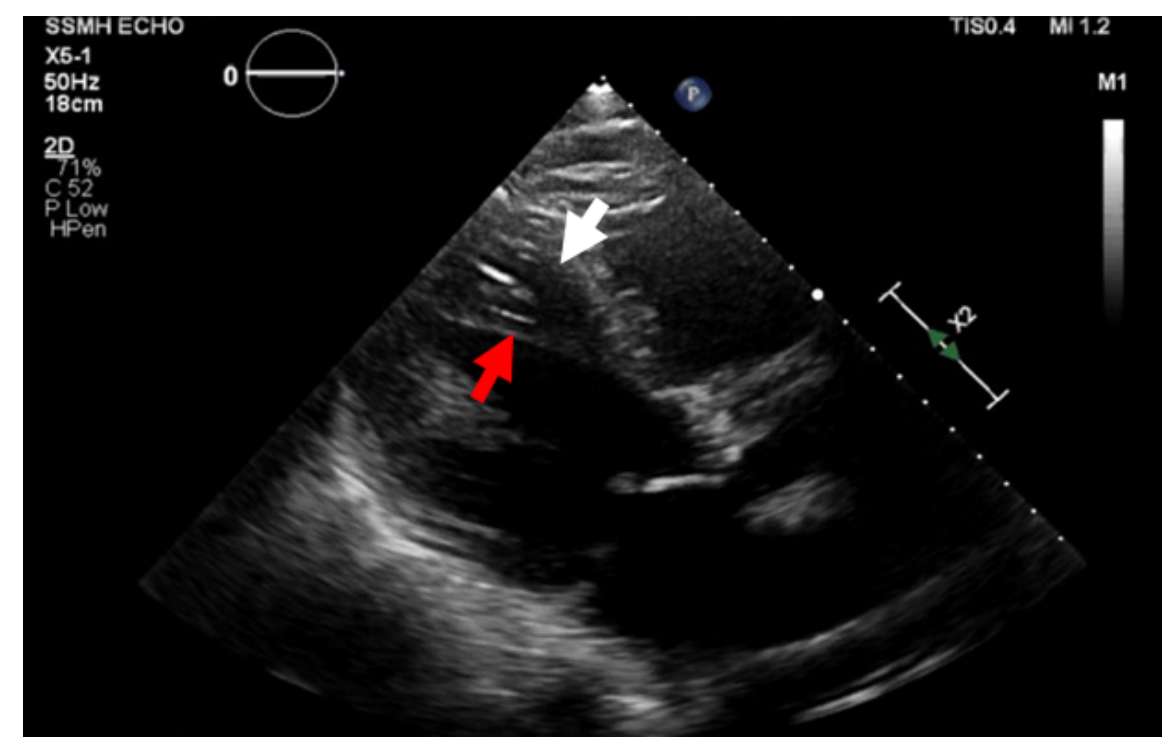

Figure 15. 72-year-old with HTN, diabetes, obesity admitted for dyspnea on exertion (PLAX).

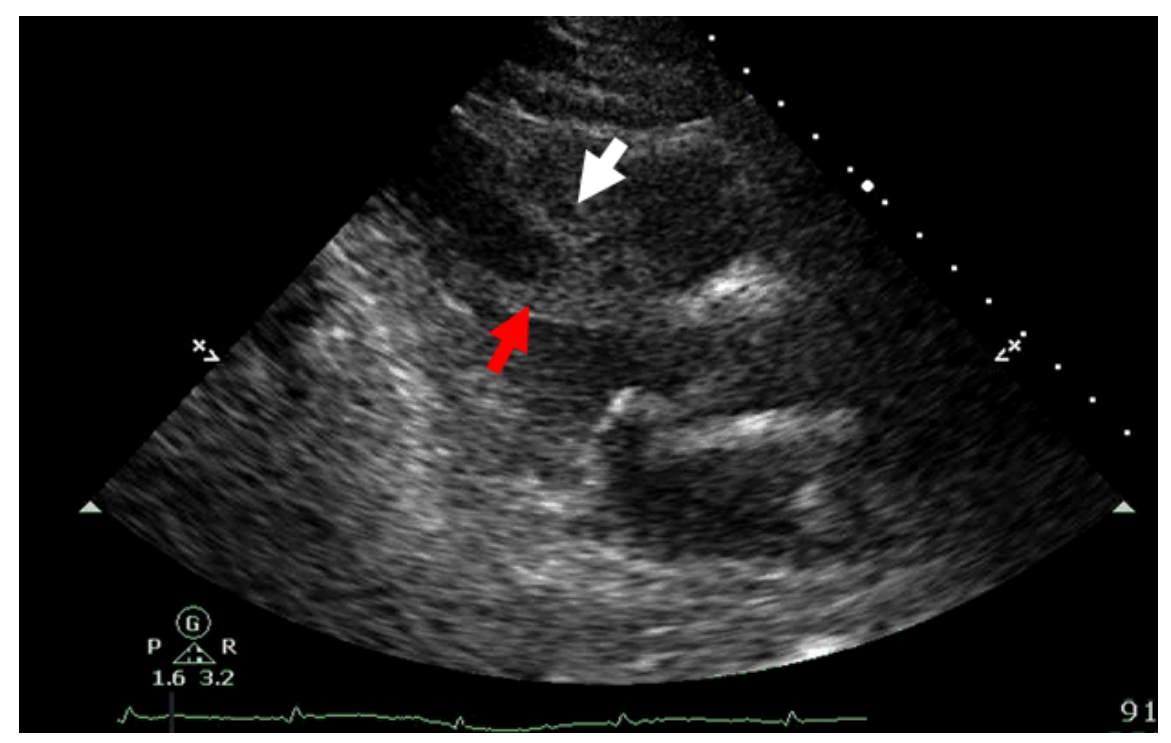

Figure 16. 71-year-old with HTN admitted for dyspnea and hypertensive urgency (PLAX). 


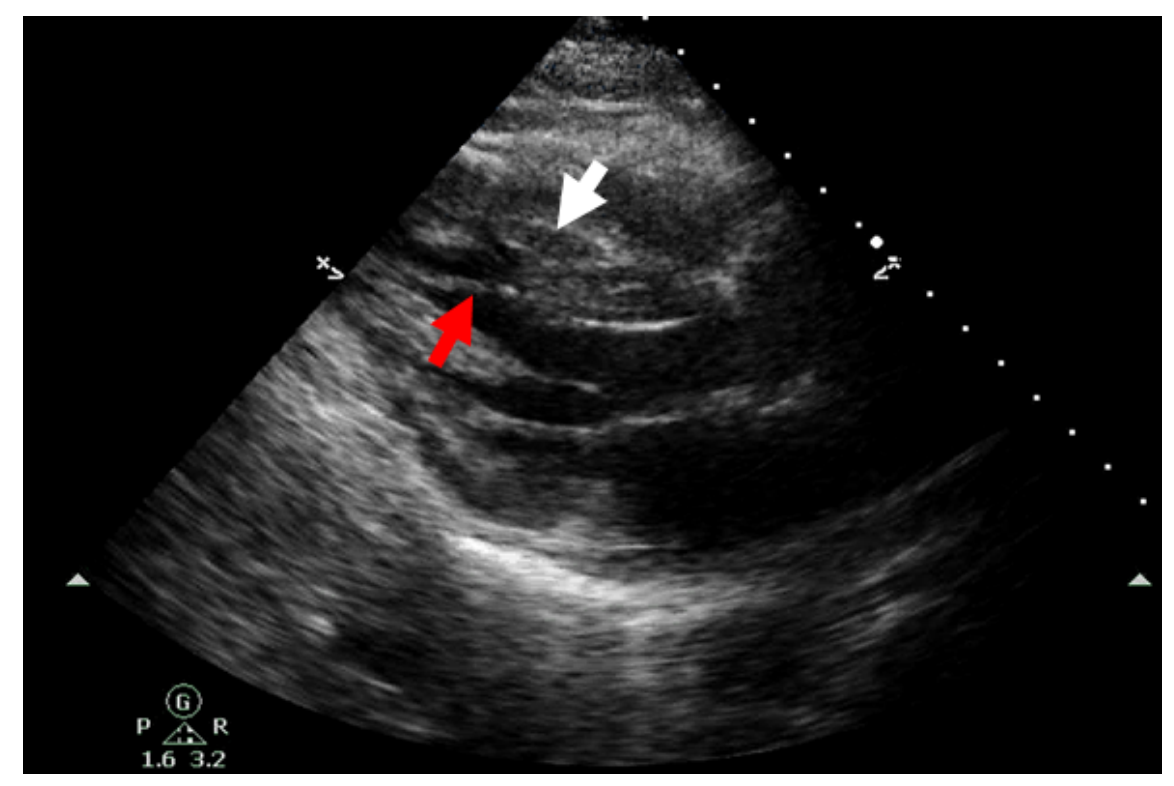

Figure 17. 72-year-old with paroxysmal A Fib, tri-fascicular atrioventricular block admitted for syncope (PLAX).

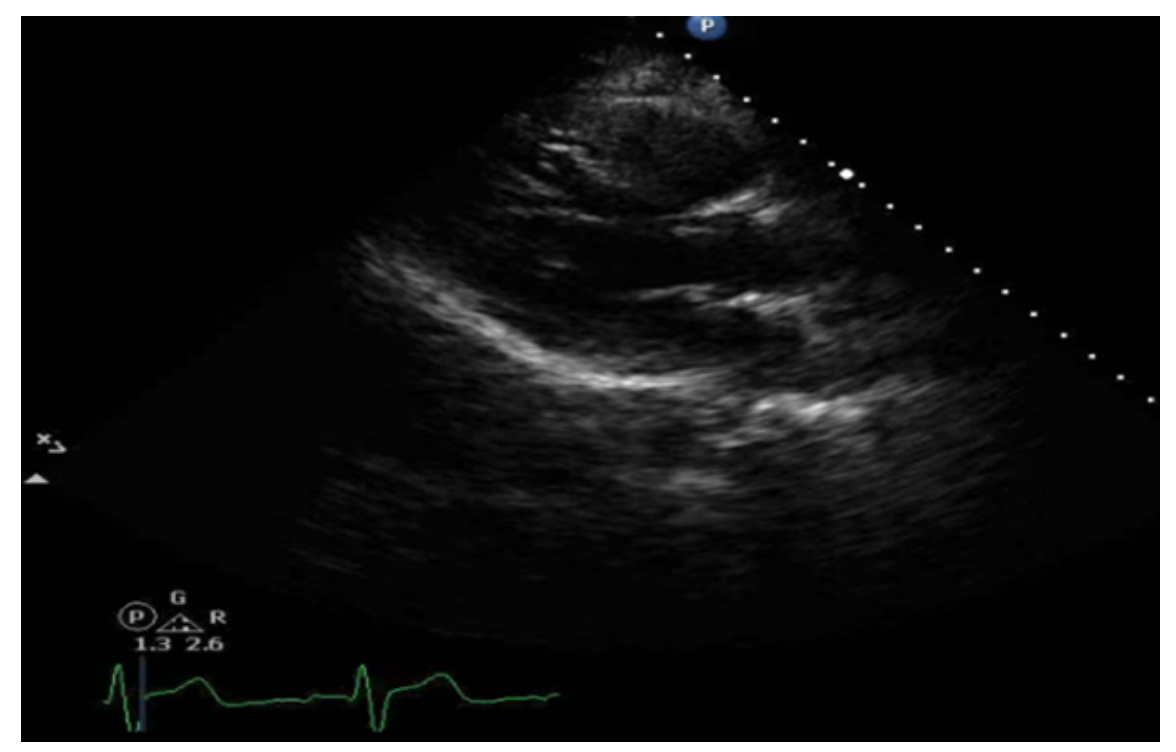

Figure 18. Echo-contrast image in a 70-year old with HTN, hyperlipidemia and CAD admitted for CP (PLAX). 


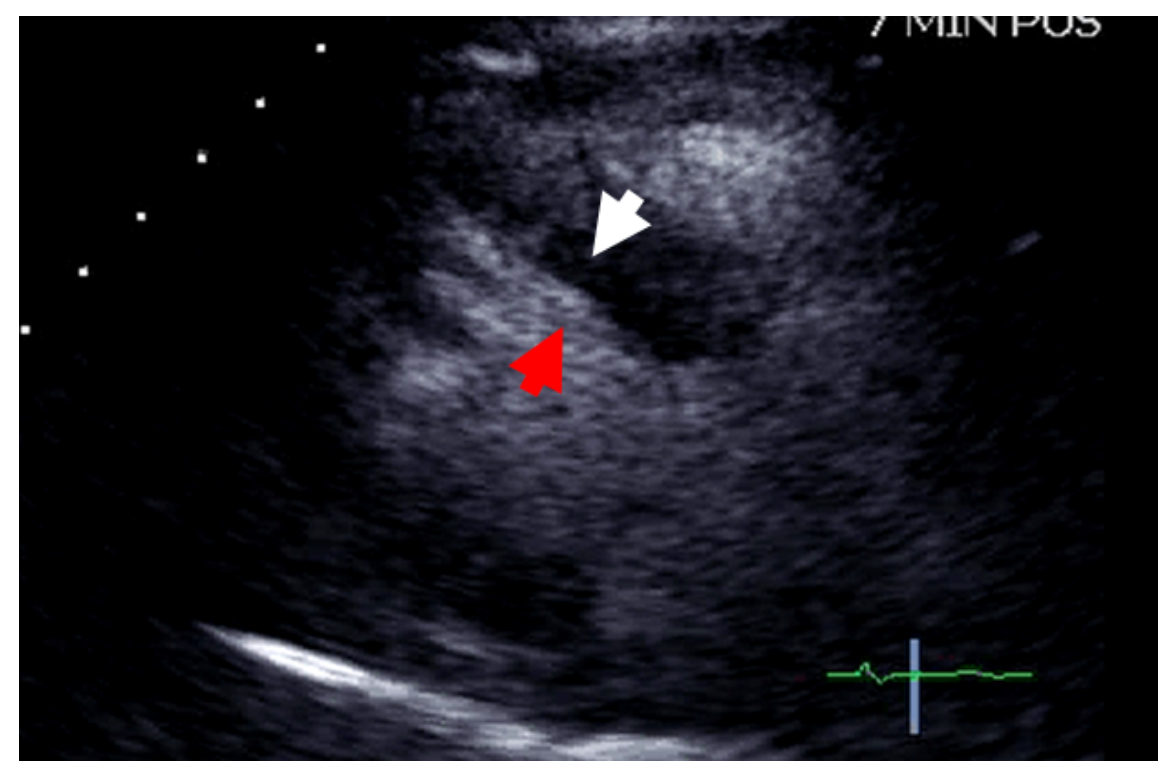

Figure 19. 43 year-old with HTN, diabetes admitted for numbness of left side of his body (PLAX).

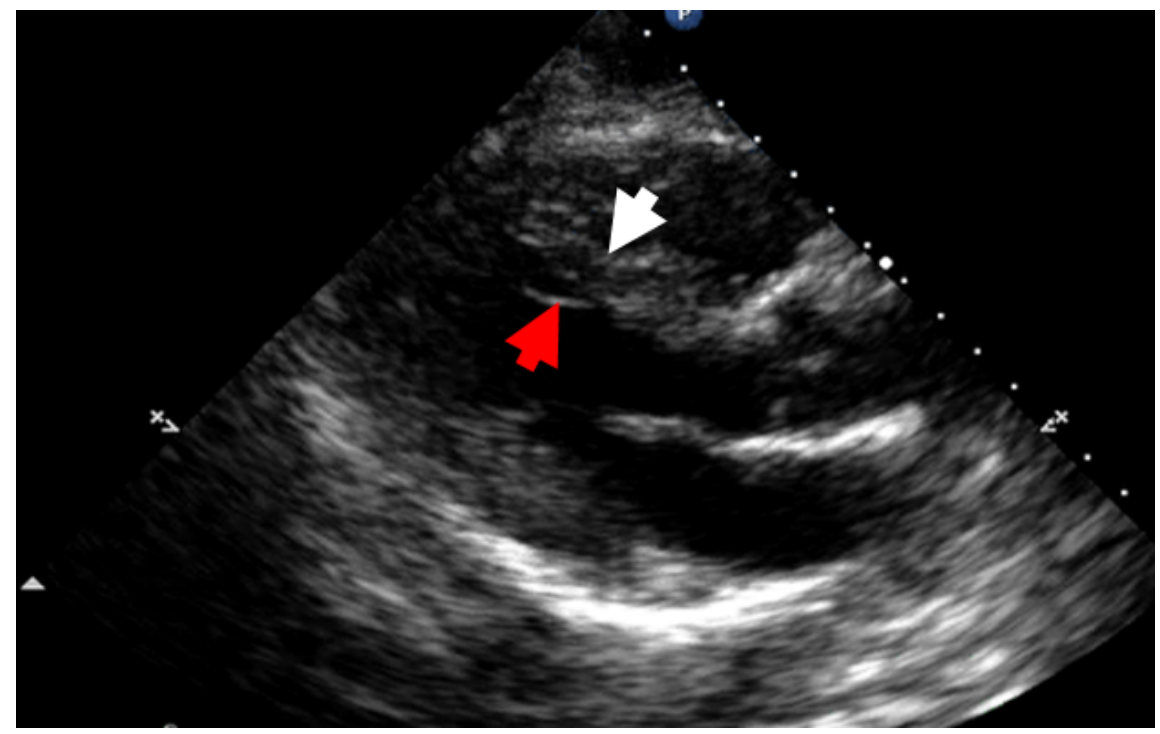




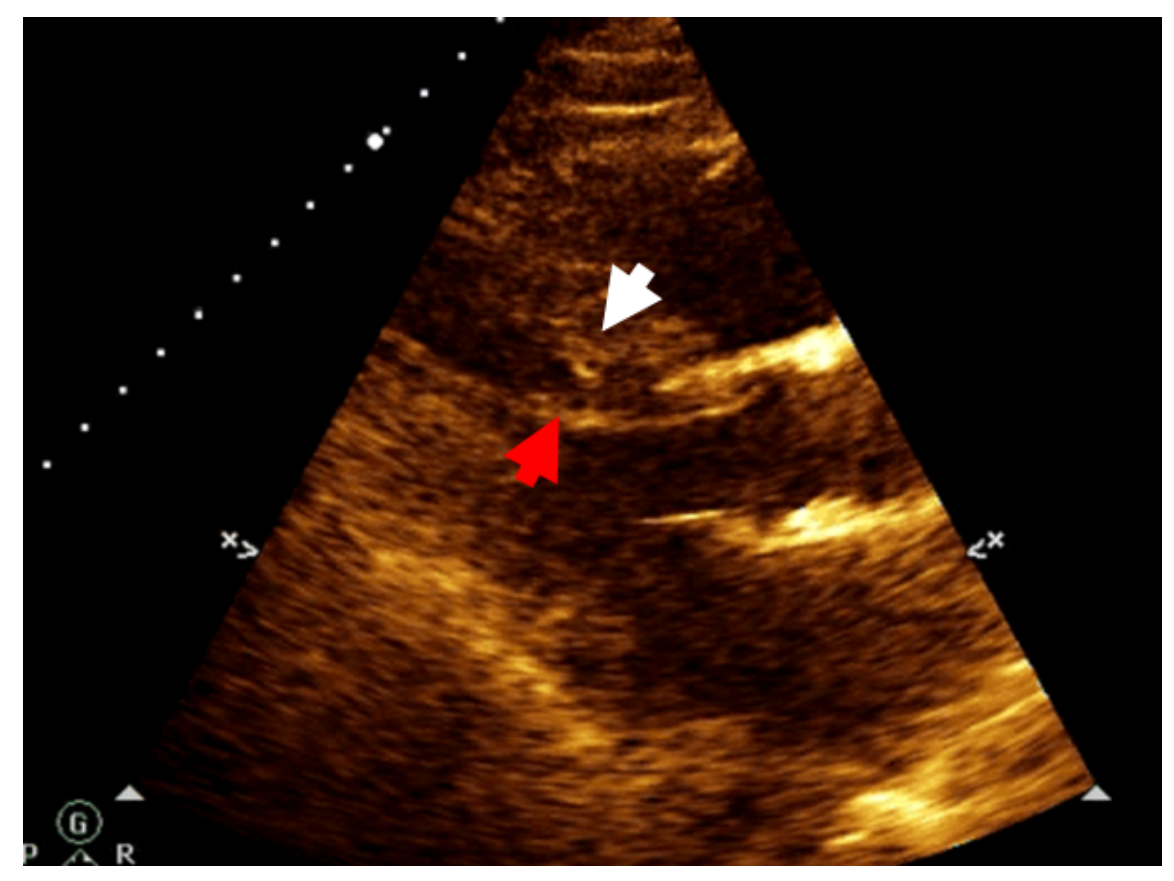

Figure 20. 80-year-old with HTN, hyperlipidemia admitted for dyspnea (PLAX).

Figure 21. 61-year-old with HTN, admitted for bleeding (PLAX).

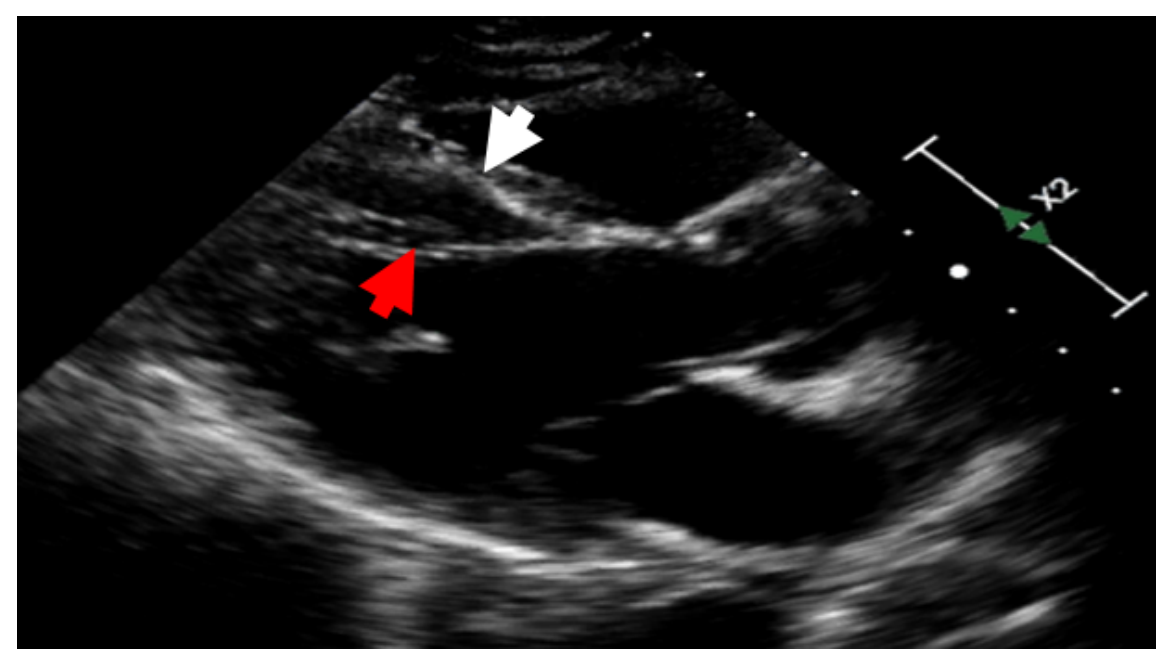

Figure 22. 91-year-old with HTN admitted for small bowel obstruction (PLAX). 


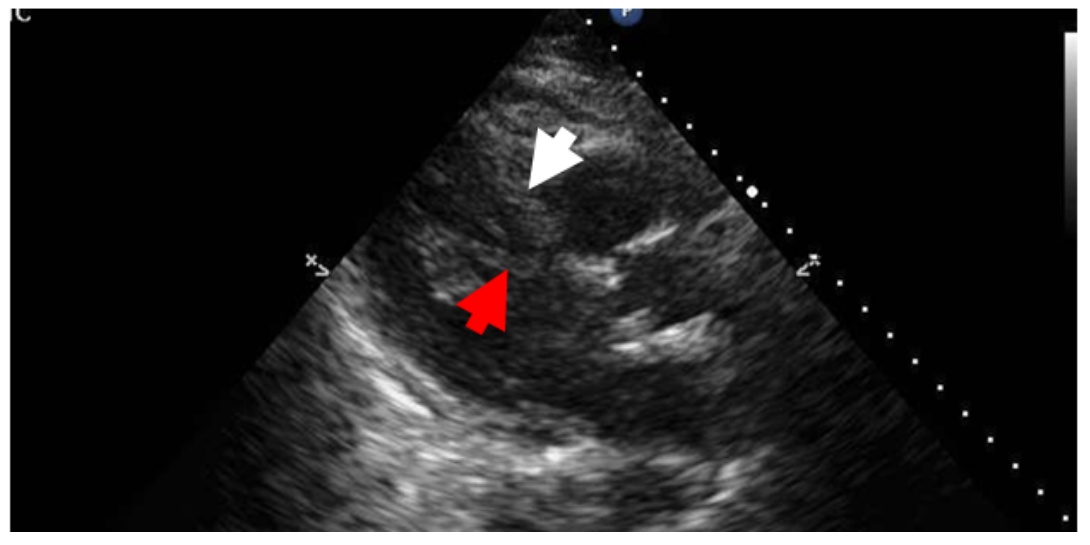

Figure 23. 76-year-old admitted for hernia repair (PLAX).

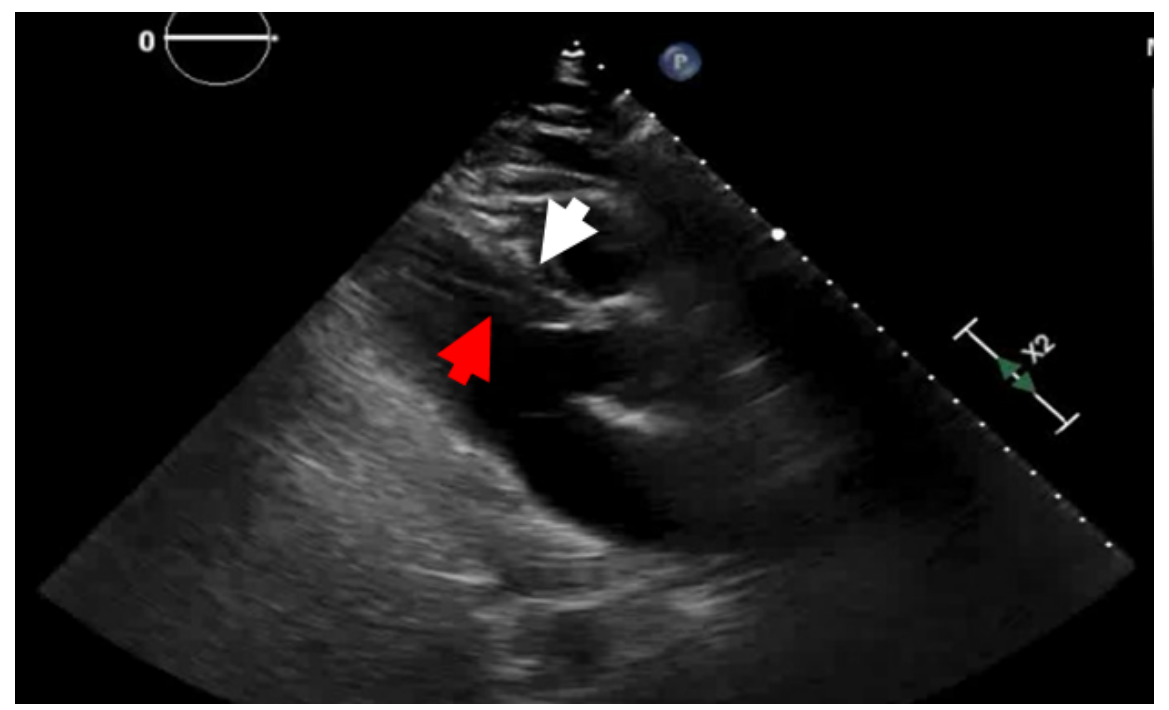

Figure 24. 82-year-old seen in the office for aortic valve stenosis (PLAX). 


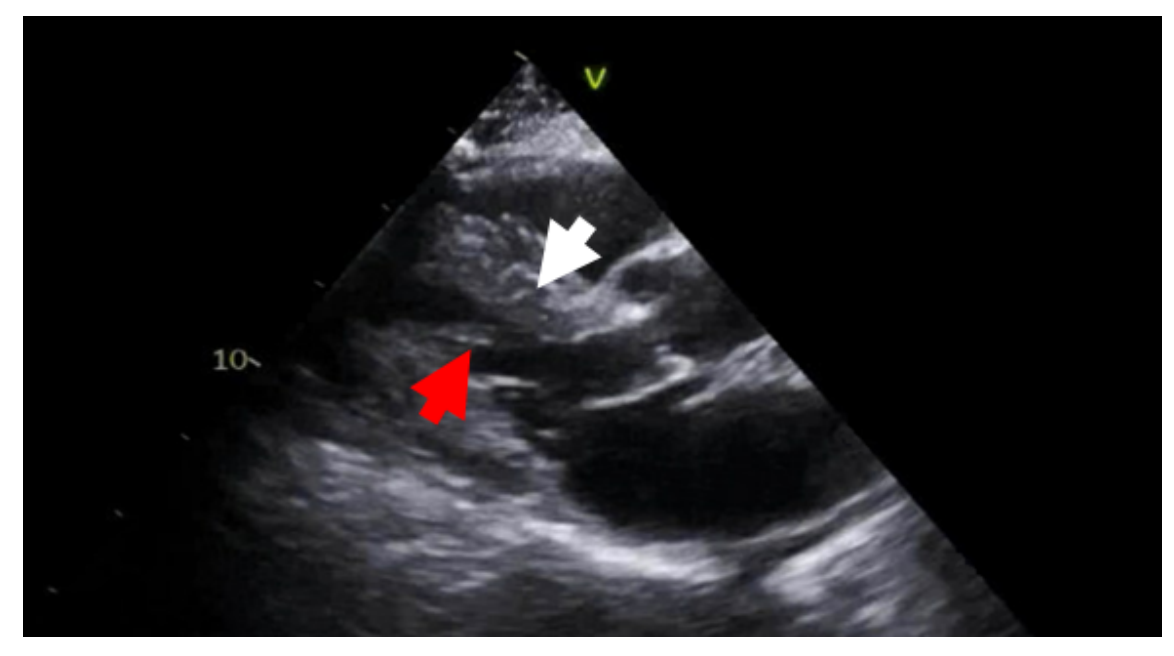

Figure 25. 78-year-old with HTN, status post aortic root replacement and AVR (PLAX).
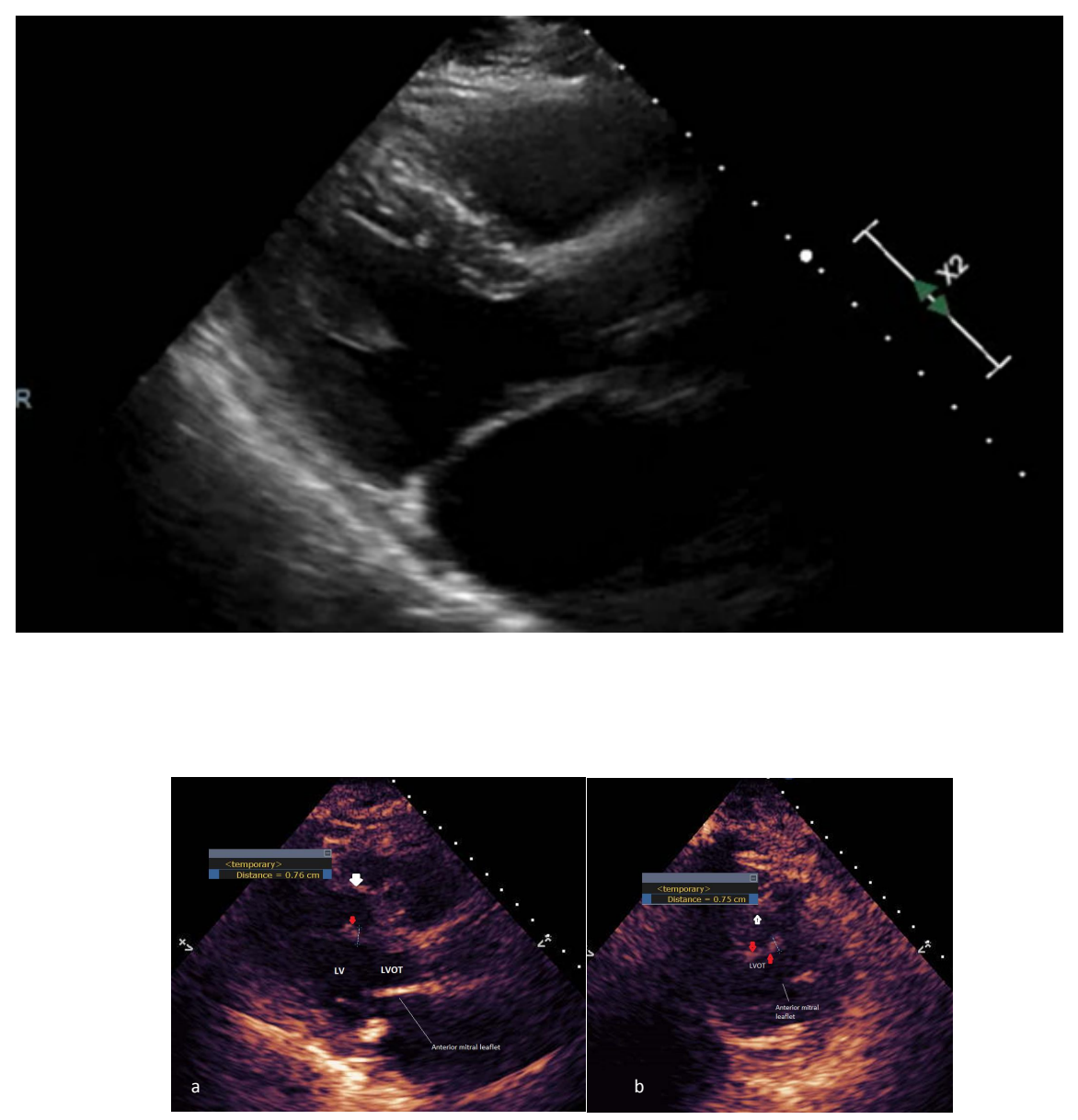

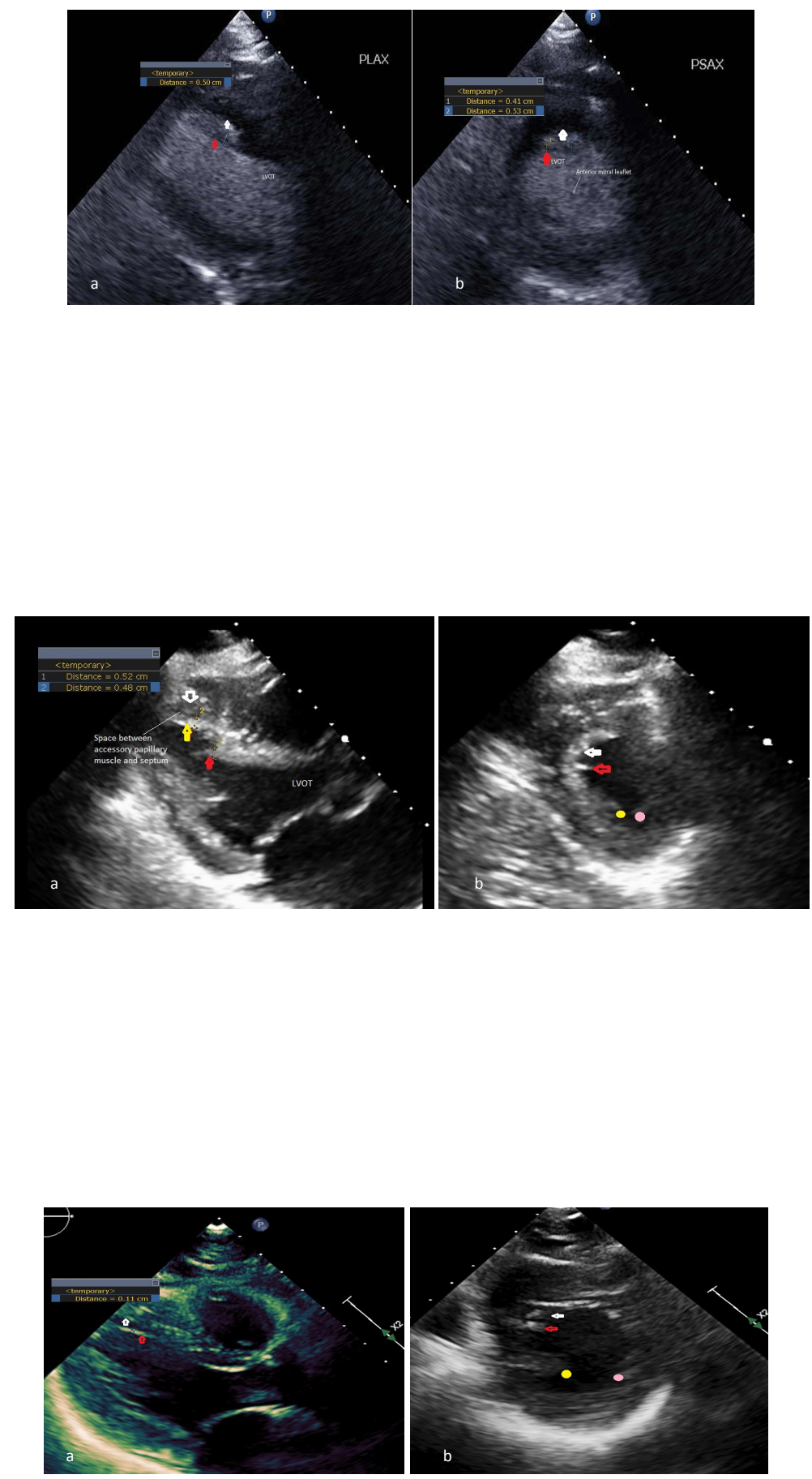


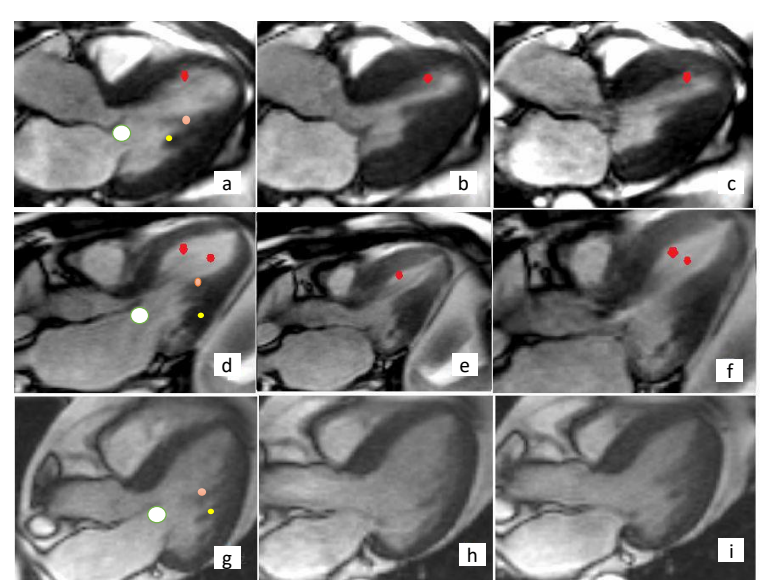

